\title{
Concrete Application as Decorative Elements in Interior Design
}

\author{
Xiaodong Zhang \\ Institute of environmental art. Hebei Institute of Fine Art ,Shijiazhuang, Hebei, 050700, China
}

\begin{abstract}
Keywords: Interior design; Concrete; Decoration; The construction
\end{abstract}
\begin{abstract}
Concrete construction has caused the attention of people since the $1920 \mathrm{~s}$, and there have been a number of outstanding architectural works vividly in front of the world. Concrete has been architects play and taste, but its application in the interior design has not been the attention they deserve. From the point of the concrete in the construction of water construction, combining with the relevant requirements and characteristics of the interior design and construction of, respectively, from the space, function, quality performance and related technology are discussed in aspects of design key points of concrete in interior design; In concrete construction procedures, respectively expounds the cast-in-place concrete and precast concrete construction procedures in the interior decoration and construction requirements; Put forward the concrete that should be paid attention to in construction after the completion of several subsequent protection measures.
\end{abstract}

\section{Introduction}

From the nature of the material such as stone, wood, mark time on concrete are deeply shallow traces of years left. Concrete surface such as skin breathing holes, bubbles, created the life growth. Concrete is such, have been found by more and more people love. "When I look at the concrete, it also looked at me in".

Today, the water concrete is still a challenge to many architects. Concrete technology development of China's late, large concrete construction does not see more, lenovo group research base is the "China's first large area concrete architecture", the designer cognition Xie Jiang said that he had just in books, only after the hands-on practice, knew real concrete kind of charm by emitting outside introversion. It skin feeling let a person produce desire to touch, it can even feel it breathing pores in fine point, it's full of spiritual affinity is comparable to any other building materials.

At the same time also have architects and designers in trying to clear water concrete in the indoor performance, such as female architect Dafna Arnon, she believes that the nature of the building from space, light, indoor and outdoor contact and detail design, some tiny elements such as furniture, art combined with concrete, colour, wood, light, the scenery penetrated into every corner of the house and change with the seasons change. She think architecture is not only its appearance, but also in the building itself. Residential facade is both unique and spectacular, although the bare concrete, give a person a sense of alienation, she managed to in their homes to create warm and intimate atmosphere. The bare, however, is still coming from the building itself, and interior design is secondary to modify and shape of building, so the water concrete elements in interior design as a kind of material and applications, from design to construction there are some differences. Material is the continuous discovery and use of natural objects, and be able to design and manufacture of various objects. The author this tradition of concrete materials in the application of interior decoration has been with great interest. The author by himself in the case of interior decoration, design and construction practice, combining with the construction of concrete in construction specification requirements and acceptance criteria, from the design point, construction procedures, subsequent protection concrete elements in interior design is discussed the application of the 
method. [1]

\section{The Definition and Evolution of the Interior Design}

Our country as the example of the interior design is defined as: "the building interior space function, technology, the integrated design of art. According to the nature of the use of the building (life or production), the environment and the corresponding standards, using technology and plastic art, human body engineering, such as knowledge, creating comfortable and graceful indoor environment, in order to satisfy the requirement of use and aesthetic."

Our country's China encyclopedia - architecture. Garden. Urban planning volume "the interior design is defined as:" part of the architectural design, to create reasonable, comfortable and graceful indoor environment, in order to meet the requirements of use and aesthetic. The main content of interior design include: building plane design and space organization, palisade structure inner surface (metope, ground, ceiling, door and window, etc.), the processing of the use of natural light and lighting and indoor furniture, lamps and lanterns, display the selection and arrangement of. In addition to plants, decoration and equipment configuration."

From what has been discussed above, we can according to the use of indoor nature, technology, economic capacity, environmental characteristics, such as related standards, design satisfy people material and spiritual life need of the indoor environment. Interior design and architectural synchronization is produced, the relationship between the two is like fish and water, and is closely related and mutually reinforcing. Interior design is a relatively independent discipline, but he's evolution and history of architecture, art history, history of art, furniture and other closely related disciplines. Whether it is a traditional Chinese or western interior design, interior design is the constant improvement of a long, spiral type of development process.

The evolution of interior design related to two factors: one is the geographical factors, including topography, geomorphology, hydrology, climate, etc.; Secondly, cultural factors, including politics, economy, religion, technology, customs and habits, etc. In the traditional Chinese interior design, for example, the ancient Chinese civilization is a multicultural and feudal centralized country, Jiangshan and introverted, scorn on economic, ideological, the author examines the determines the direction of Chinese traditional interior design, with farming local and national character, Confucian color and bright color.

\section{Interior Design and Architectural Design of the Differences}

In a broad sense, the architectural design and interior design belongs to the category of architecture, it is impossible to completely separate between them. Some scholars think: "is part of the architectural design, interior design is an integral part of building design. A good building, the exterior and interior space design must contain the two basic content." Despite the architectural design and interior design have many similarities, they all want to consider the formal beauty on the modelling, for example, use the function of the United States, the user's aesthetic, at the same time they also restricted by economic and technical conditions, architectural design and interior design still have very big difference.

Today, the water concrete is still a challenge to many architects. Concrete technology development of China's late, large concrete construction does not see more, lenovo group research base is the "China's first large area concrete architecture", the designer cognition Xie Jiang said that he had just in books, only after the hands-on practice, knew real concrete kind of charm by emitting outside introversion. It skin feeling let a person produce desire to touch, it can even feel it breathing 
pores in fine point, it's full of spiritual affinity is comparable to any other building materials.

At the same time also have architects and designers in trying to clear water concrete in the indoor performance, such as female architect Dafna Arnon, she believes that the nature of the building from space, light, indoor and outdoor contact and detail design, some tiny elements such as furniture, art combined with concrete, colour, wood, light, the scenery penetrated into every corner of the house and change with the seasons change. She think architecture is not only its appearance, but also in the building itself. Residential facade is both unique and spectacular, although the bare concrete, give a person a sense of alienation, she managed to in their homes to create warm and intimate atmosphere. The bare, however, is still coming from the building itself, and interior design is secondary to modify and shape of building, so the water concrete elements in interior design as a kind of material and applications, from design to construction there are some differences. Material is the continuous discovery and use of natural objects, and be able to design and manufacture of various objects. The author this tradition of concrete materials in the application of interior decoration has been with great interest. The author by himself in the case of interior decoration, design and construction practice, combining with the construction of concrete in construction specification requirements and acceptance criteria, from the design point, construction procedures, subsequent protection concrete elements in interior design is discussed the application of the method.

First, the building design is to design a building or buildings have to do all the work, more emphasis on comprehensive. It to solve problems include: building inside all sorts of use functions and the use of the reasonable arrangement of space, buildings with the surrounding environment, and the coordination of various external conditions, the art of interior and exterior effect, every detail of the construction methods, construction and structure, Construction and comprehensive coordination of various equipment and related technology, and how to use less material, less labor, less investment, less time to achieve the above all kinds of requirements. Interior design, however, is just to deal with a specific space environment, through the internal space modelling, interior lighting, colour and decoration create a space atmosphere. Thus it can be seen, the focus of architectural design and interior design is different, on the overall and comprehensive is also very different.

Second, the architectural design is the precondition of interior design, interior design is a continuation of the building design, is further architectural design into daily life. Both according to the working phase partitioning in construction engineering structure to finish for limit, before design for the building, after is interior design. Many buildings can exist for a long time and even hundreds of years, but the interior design will be as the change of function, the change of The Times, constantly updated, buildings are not the same cultural connotation and aesthetic meaning.

Third, indoor design covers the content, with the development of social economy, stretch out. The specific content of the current interior design mainly include: space design, interior decoration design, furnishings and furniture design, indoor physical environment design. But the object of interior design is not always confined to inside buildings, such as airplanes and ships within the cabin space design, also with a strong interior design features, also belong to the category of interior design.

\section{Interior Design and Architectural Design of the Inner Link}

While architectural design is the premise of interior design, architectural design and interior design of the internal connection design of the whole process from beginning to end.

First, before the construction of buildings, the designer shall, in accordance with the construction 
tasks, the construction process and the use of the existing and possible problems in the process of, to make a whole idea, that is to say, in the architecture design stage of the prophase work, consider the positioning of interior design is a must, otherwise, sometimes in order to make up for the defect of the original architectural design, or for the need of new features, and transformation of existing buildings can cause a lot of unnecessary waste of manpower and material resources, financial resources, time. Architectural design and interior design at the same time, supplement each other, to avoid unnecessary loss.

Second, the architect is created by the structure of the overall, the relationship between time and space and interior designers to create buildings within the specific relationship of time and space, has a very close relationship between the two. In the design of the building at the same time, the architect must have profound knowledge of interior design, in the structure of the design phase to the completion of the internal space of effect to make full consideration, provide conditions for the interior designer's creation in the future. Also, interior designers should fully understand the architect's creative intention, use all kinds of means, create the ideal internal environment.

Again, indoor design to follow the technical standards, are mostly the architectural design of technical standards, such as architectural design, fire control, hygiene standards, and so on. For the beginners of interior design, good grasp of the knowledge of building architecture is especially important how such as a house is built, it consists of what elements, what are the requirements for its structure, etc. Architectural design in the design specifications, standards, as well as some related basic knowledge of the rules of formal beauty and building physics is also indispensable knowledge reserves.

Finally, both in architectural design and interior design is to follow the whole design idea guidance, at the time of rendering large designed for mutual coordination and synchronization is perfect, a good architecture is dependent on the success of interior design, interpretation space build atmosphere of success to be able to add luster for architectural design interior design. This requires a interior designer in the indoor design, grasp big policy, development thinking, through to the interior space to create, build in harmony with the architecture and the external environment and space atmosphere full of vitality and artistic appeal, make the building has its own characteristics at the same time, it reflects the personality of interior design.

At the same time also have architects and designers in trying to clear water concrete in the indoor performance, such as female architect Dafna Arnon, she believes that the nature of the building from space, light, indoor and outdoor contact and detail design, some tiny elements such as furniture, art combined with concrete, colour, wood, light, the scenery penetrated into every corner of the house and change with the seasons change. She think architecture is not only its appearance, but also in the building itself. Residential facade is both unique and spectacular, although the bare concrete, give a person a sense of alienation, she managed to in their homes to create warm and intimate atmosphere. The bare, however, is still coming from the building itself, and interior design is secondary to modify and shape of building, so the water concrete elements in interior design as a kind of material and applications, from design to construction there are some differences. Material is the continuous discovery and use of natural objects, and be able to design and manufacture of various objects. The author this tradition of concrete materials in the application of interior decoration has been with great interest. The author by himself in the case of interior decoration, design and construction practice, combining with the construction of concrete in construction specification requirements and acceptance criteria, from the design point, construction procedures, subsequent protection concrete elements in interior design is discussed the application of the method. 
For building, architectural design and interior design is like a person's body and internal organs, no matter the missing part, he cannot constitute a complete person. Architectural design of the structure, the epidermis, the internal division space, etc., are designed for indoor a necessary condition for the existence of and provide more possibilities. Space atmosphere of interior design, function layout, decoration is in perfect architectural design integrity to provide sufficient conditions. Interior design make this one space environment has both use value, meet the functional requirements, but also reflects the historical context, architectural style, mental factors such as environment atmosphere. That is why many scholars all think: indoor is the building.

The soul, is the contact person and the environment, is the combination of art and material civilization. "

1895 American women coalition "interior design association" is the source of the word "interior design" the earliest. Modern interior design in the second world war gradually developed into an independent professional. Since the eighty s of the 20th century, China's burgeoning interior design. Looking to the future, the end of the interior design will remain open, it will change with the changes in the architectural design and other arts trend of synchronous development, aesthetics, philosophy, human body engineering, environmental psychology, physics and so on, it will with the change of the society as a whole is harmonious, harmony with the progress of science and technology, and human deeper understanding about its harmony.

\section{Indoor Design Key Points of Concrete Elements}

Concrete can be regarded as a decorative art. It is a strict formula proportion of concrete pouring, after the demolition of casting template, no longer to besmear to brush, decorate, retain the original texture, concrete directly presents the real appearance of the concrete. Concrete wall surface is very smooth, angular, solemn, simple. Someone said "it's like a newborn baby beautiful and mysterious, have experience of construction personnel can describe it in front of the mold release" [2].

From the Consideration on the Space. For most buildings are not concrete structure, the performance is needed in indoor water concrete is required for a material to casting or the use of precast concrete decorating plate, and usually when pouring concrete such as the thickness of less than $50 \mathrm{~mm}$ will shell [3], so the minimum thickness shall not be less than $50 \mathrm{~mm}$. And precast concrete dry hanging decorative sheet can be used and production base at the grass-roots level to cover processing, dry hanging embedded accessories and decorating plate thickness is about 100 mm [4], production base at the grass-roots level to the construction and the thickness of around 50 $\mathrm{mm}$, so will take up a lot of interior space, large area is used in the design space should be given due consideration.

Considering from the Function. Clear water concrete pouring and install a forming, therefore should take full consideration on the function positioning and reserved, such as orientation of switch socket, water and electricity road line and reserved, metope embedded parts, accessories and reserve, etc. In addition, cast-in-situ concrete and dry hanging and render a face the stress of the precast concrete strength each are not identical, so the concrete construction method and material selection should be based on function requires reasonable selection.

From the Consideration on the Quality Performance. Concrete because of its color and texture can form a plain and simple sense, but also can produce the feeling of cold and stiff, so when the design should be properly configured according to indoor environment demand, give full play to the characteristics of concrete and charm. Color, such as adjusting concrete and wood, leather, fabric and other material combination collocation, the feeling of tenderness; Also can be combined and metal, glass and other materials to build a modern industrial technology of beauty. As 
and logs, stone and other natural material collocation, can bring people the feeling of a kind of simple, elegant. In all appropriate use of the characteristics of the concrete itself can show indoor space natural harmonious beauty. It will no longer be the people in the eyes of the humble, hard, cold building and structure material, as Xie Jiang of clear water concrete a good metaphor, he said: concrete like a splash-ink landscape, in the continuous casting of concrete will be cold seam, make concrete effect like a splash-ink, and poured out what, conveniently and designer. So it showed the effect is different every time. From this sense, the concrete is more like an art.

From the Consideration on the Technology. Should be according to the actual situation choose the concrete way of fabrication and installation, save cost and shorten time limit for a project requirements. From the design point of view such as templates, or template cutting loss material control, can choose average uniform segmentation and middle or on either side of the closed edge; Bolt hole water concrete is the sign of recognition, from mechanical considerations should also be in uniform isometric Settings to meet safety requirements; Choose smooth texture template for the template or take effect will be different. At the same time should also give full consideration to doors, Windows and the detail processing of different materials on it way and way of construction.

\section{The Construction Technology of Preparation}

Basic Processing. Before using cast-in-place concrete, foundation walls should be clean, check whether there is the original wall cracking, empty drum, the phenomenon such as a shell. If the original wall of ash handling, in order to make concrete combined with the original metope is firm, batch of ash layer should be after MAO or eliminate use of steel mesh. Use of precast concrete decorating plate adopts the practice of grassroots render, should choose high strength, good toughness, flat and smooth the surface of the plate to render at the grass-roots level. If use dry hanging concrete decorating plate, hang should be accurate, installation is firm. Before construction metope waterway circuit transformation should be completed construction, metope is embedded, reserved, positioning and processing is complete check and acceptance.

Template Engineering. Mainly for the concrete engineering, water in cast-in-site concrete construction, template engineering is the key to meet the requirements of concrete. Because of concrete used in interior decoration, the more strict quality requirements and acceptance standard, with reference to the Beijing shooting range prefabricated concrete outside hangs Taiwan special standard "and" the construction engineering construction quality acceptance.

Unified "GB50300-2001, as well as himself through many times in the application of concrete performance of interior design, summed up the template should reach the product quality standard.

Template Design. According to the structural characteristics of the modelling design reasonable choice template materials, and according to the site according to the standard size, the principle of integration, generalization to reasonable partition template in order to achieve the effect of the symmetrical, uniform and especially the block diagonal model and the way of lap joint should be comprehensively considered. Reasonable template design to make the water concrete engineering as to meet the requirement of high quality, high efficiency, cost control.

Templating. Template template processing production is mainly control the flatness, straightness and verticality. Concrete for concrete surface color, tiny bubbles evenly; By regularly to the bolt hole, Ming sewing, zen seaming combined with natural texture as the finishing effect. Therefore, the concrete quality of making stencil materials have higher requirements. Template design of concrete shall be determined according to the design drawing of component detailed Ming sewing, zen seam, location and size of bolt hole distribution board.

Requires the Point for the Structure of the Template. The shade (1) component parts of the 
template should configure horn die or mould fittings, colorful shade mould with the adjacent template have reliable connection, in order to guarantee the accuracy of the component's point of view; If use wooden template, Yin Angle on either side of the template and stare blankly should need by plane flat Angle of light, docking accurately control Angle to each other.(2) the template surface joint namely zen, appropriate in a stare blankly at the back, in order to avoid the plate height difference or slurry. (3) components part of the template should match ChengYang Angle mode or Yang Angle fitting. Yang Angle mode with the adjacent template reliable link to guarantee the accuracy of the Angle. If use wooden template, side plate should be dressed stare blankly Angle plane as required, make the template Angle on both sides of the accurate, tight lap.(4) concrete wall end template face template should be embedded in the side of the wall inside the template, in order to keep the end Angle accurately.(5) on the installation of bolt not only have the ability of new pouring concrete side under pressure, but also the surface of the water concrete effect, according to the principle of uniform configuration. Some not bolt to display on the part of the bolt hole, need to make decorative hole, often referred to as "eye"; Appropriate use of bolt plug is fixed on the template, the formation of such decorative holes.(6) to leave a hole on the surface of the concrete, the material could be selected according to the characteristics of the hole, the hole of the template size must be accurate, the template should be fixed tightly, tight connection, convenient and concrete pouring. Therefore, on the edge of the template to stick a sealant, prevent leak slurry; Bit at the bottom of the hole on the template of the need for exhaust secrete hole; Width of the larger hole of the need for feed opening, so that the blanking and vibrating. Feed opening can be closed the cover, under water the adit opening sealed along with the cover plate, a trace on the surface of the concrete.(7) plate division should consider when the configuration template, facilitate the production and installation; Also consider the relationship of the plate, the installation of template, remove the step by step, easy for complete removal.

Template Installation. Template before installation should count templates and accessories, confirm the type and quantity. Check side stare blankly is complete without damage to maintain good sealing. Template surface should be without sundry besmirch, scratch injury, steel template board face no rust, paint template complete, firm adhesion; If there are any local damage, should use the same material repair smooth, clean, complete in time for replacement if necessary. At the same time to check attached on the template of the reserved hole, box and accessories, to ensure that the connection is firm and cleaning degree requirements; Check the template fitting degree of fastening, ensure that can connect firmly. Check equipment piping installation is complete, metope is embedded and reserved, positioning, is completely conform to the requirements of the installation. Check the rear installation can be performed. When installation should pay attention to the following points:

(1) shall be determined according to the plan of the installation order, according to the template code in place, to ensure flat-fell seam tightly and convenient after demolition.

(2) Installation template should be built for the necessary temporary support frame and operation frame, make the hoisting in place not correct, fixed template has a stable, ensure the safety of the construction is convenient,. Hoisting template, to properly protect the template surface and edges, prevent damage, not bending, impact to the template.

(3) template should connect closely, template seams spell leakproof slurry measures shall be complete and effective. Installation of bolt and fittings should correctly counterpoint, pry damage may not be hard to pull hard template; Tighten the order, should pay attention to in the bolt installation lock degree; Template support system, complete fittings should be set, the top and fixation. 
(4) the water concrete external wall should be made clear in a horizontal construction joints seam. The template should be on the special seat. Supported by stent template dead weight, compaction template roots, positioning and fixed effect. Support with bolt, top bracing in proper positions below the construction joints of concrete structures. On contact surface of the need for cushions top bracing and concrete, under the protection of construction joints of concrete surface. In addition, the outer edge of the beam template should be supported in column template for the top, the second beam template should be supported in the outer edge of the main girder template for the top, and seals in the cracks.

\section{Indoor Concrete Construction Procedures}

Cast-in-situ Concrete Construction. The preparation of the concrete, must be considered to meet the construction requirements of liquidity, and segregation resistance; And vibration molding or self-compacting, can get the surface of the dense, in addition, must meet the requirements of the compressive strength, guarantee the durability and reduce dry shrinkage, avoiding cracking. The slump should be controlled within $12 \mathrm{~mm} \sim 18 \mathrm{~mm}$.

Before mixing ratio to determine, should try to match, and the construction model of experiment, determine the proportion, mixing must strictly according to the proportion of the construction.

Layering water concrete wall to, blanking, vibrating, blanking is super thick accumulation, super thick accumulation is insufficient areas prone to vibration or vibration, defects; Line in the window is a class template within the narrow space, should take care all the more, likely coarse aggregate stuck situation, need people to work at this time. At the end of beam and column joint left by twice before pouring construction joints, the column catchy template must be tightened again, to reduce the size and the gaps between the concrete, avoid secondary after pouring in cap and fault phenomena, it also can reduce mortar infiltration, leading to lower water concrete color inconsistencies. Concrete should be maintained at least reach $14 \mathrm{~d}$ after casting.

Precast Concrete Decorative Construction. (1) according to the elevation of building is given first line and benchmark locating on the edge of the line, according to the structure of the deviation to determine hangs Taiwan plane position of interval size whether meet the requirements of installation.

(2) hangs Taiwan by welding the steel bracket and install fitting with a fixed structure, the installation of the steel bracket height directly affect the quality hangs Taiwan installation, smoothness and aperture size and robustness. So first need to ensure the welding quality of steel bracket, such as the length and thickness of the weld whether meet the requirements of the drawings, in addition to strictly control the size of steel bracket positioning accuracy, namely the top surface of steel bracket elevation should be controlled in plus or minus $2 \mathrm{~mm}$ before and after, left and right deviation control in the plus or minus $3 \mathrm{~mm}$, for plus or minus within $2 \mathrm{~mm}$.

(3) hangs Taiwan from bottom to top in turn level installation, after installation to the top again, respectively, on both sides to full range wall after the installation, then humanly scaled hangs Taiwan sewing glue processing parts, in case of the rain into the hangs Taiwan.

\section{Concrete Protection}

Concrete construction completion after demoulding, may be caused by dry shrinkage cracking, freezing and thawing cause discoloration and damage, but also because of the collision and subsequent construction dust on the concrete damage and pollution, so should be timely after demoulding to protect the water concrete walls. Considering concrete construction follow-up 
protection measures are as follows.

Protectant before use to ensure the concrete curing period to $28 \mathrm{~d}$ left and right sides, after completion of maintenance, the concrete surface cleaning and brushing primer and middle-level paint, according to the need to add a little color in the protective primer, makes concrete to keep the same color and meet the design requirements. For the overall construction completed, final paint in construction of wall paint and then to finish the construction.

Concrete demoulding and after besmear to brush the primer and middle paint should be timely with plastic film mulching, plastic film if there is damaged, it should be replaced in a timely manner. The plastic film lap of finished product protection should be adopted under plastic film pressure on the plastic film, and USES the wide tape seal, but must avoid direct contact with the concrete surface width tape. At the site of the staff can reach and door, Yang Angle parts of the column, the channel need to paste the hard plastic or old template, it is advisable to height in $1.8 \mathrm{~m}$ or so, prevent destroyed by human in the process of material handling.

\section{Conclusion}

With the continuous development of comprehensive technology of concrete, concrete as a kind of traditional building materials, has bloomed its unique charm in the sight of people, its technology and products have been can meet the demand of application in the interior. To sum up, as long as in the design, construction and subsequent protection attention, clear water concrete in interior design is also a kind of very good adornment material, believe that by the majority of the designers of the water concrete gradually realize and untiring attempt, in the near future, concrete to the mysterious and elegant, simple and vigorous world materials shall shine brilliantly in interior design.

\section{References}

[1] Ma Jian-mei. Environmental art course teaching mode reform of professional landscape design [J]. Anhui Agricultural Science. 2011 (31)

[2] Tang Jun. The development of modern landscape design present situation and trend analysis [J]. Chinese Gardening Abstract. 2012 (9) : 97-2012.

[3] Han Yu. Experience type teaching, the landscape design course teaching practice research [D]. Nanjing: Nanjing College of Art. 2012

[4] Suo Liya. The exploration and research of "project engineering room" in the teaching of interior design specialty in Higher Vocational colleges. Journal of Chongqing Education College. 2012 (6): 127-128

[5] Wang Lijiong. On the teaching reform of interior design studio teaching in Higher Vocational education. Jiannan literature. 2012 (7); 294-295 